\title{
Study on the synergy between intra-urban resident's migration and job change in Beijing
}

\author{
YU Jianhui ${ }^{1,2}$, DONG Guanpeng ${ }^{3},{ }^{*}$ ZHANG Wenzhong ${ }^{1,2}$, LI Jiaming ${ }^{1,2}$
}

1. Institute of Geographic Sciences and Natural Resources Research, CAS, Beijing 100101, China;

2. Key Laboratory of Regional Sustainable Development Modeling, CAS, Beijing 100101, China;

3. Sheffield Methods Institute, Faculty of Social Sciences, The University of Sheffield, Interdisciplinary Centre of the Social Sciences (ICOSS), 219 Portobello, Sheffield S1 4DP, UK

\begin{abstract}
People's decisions of residential mobility in housing market and decisions of job change in labor market play an essential role in the formation and dynamics of urban spatial structure. This paper investigates the relationship between residential relocation and job change and its heterogeneity using a large-scale survey of residential living satisfaction and preferences in Beijing. Several conclusions are drawn as follows: 1) People's decisions of residential mobility are significantly positively correlated with their decisions of job change, indicating that these two-dimensional decisions are in fact a correlated decision process rather than two independent decision processes. 2) There is heterogeneity in the correlated decisions of residential mobility and job change. More specifically, the interrelationship between the decisions of residential mobility and job change among people without Beijing hukou, renters and single-worker households is more intensive than people with Beijing hukou, homeowners and multi-worker households. In addition, there is heterogeneity in the determinants of residential relocation and job change between groups with different types of housing tenure, household registration status and family employment structure. 3) For renters, commuting time can significantly increase the probability of residential relocation, which indicates that residents of different socioeconomic attributes have very different responses to commuting time costs.
\end{abstract}

Keywords: residential mobility; job change; bivariate discrete choice models; Beijing

\section{Introduction}

Living and working spaces are two important components of urban spatial structure. Residential location choice and residential mobility has attracted attentions from a wide range of

Received: 2014-01-14 Accepted: 2015-03-05

Foundation: National Natural Science Foundation of China, No.41201169; No.41230632; Key Program of Chinese Academy of Sciences, No.KZZD-EW-06; National Science and Technology Support Program, No.2012BAJ15B02

Author: Yu Jianhui (1983-), PhD, specialized in residential space distribution and its evolution mechanism. E-mail: yujh@igsnrr.ac.cn

*Corresponding author: Zhang Wenzhong, PhD and Professor, E-mail: zhangwz@igsnrr.ac.cn 
fields such as sociology, urban economics and geography. Residential migration, generally considered to be a behavior of residents within a single housing market, is the process of residents adjusting their housing according to the gap between current housing conditions and housing demands or expectations (Brown et al., 1970, Rossi, 1955). Various family structure factors such as an increase of family size, formation of new families, divorce, and retirement have important impacts on migration (Clark et al., 1982, Ermisch, 1999, Li et al., 2001, Clark and Huang, 2003, Aassve et al., 2007). In addition, house equity is directly associated with the cost of housing adjustment. The adjustment costs for house owners are larger than renters and so is the degree of dissatisfaction that house owners can endure. Thus, the possibility of residential migration for owners is less than that for renter, ceteris paribus (Clark et al., 1999). Resident's family employment structure (Clark et al., 2003), contextual factors of residential community (Lee et al., 1994, Rabe et al., 2010), housing market supply constraints (Van et al., 1998) and other institutional factors are also found to be significant factors of residential mobility. However, only a few studies focus on the relationship between job changes and residential migration. Clark and Withers (1999) found that given other factors, job change is an important predictor of residents' housing adjustment decisions. When individuals' workplaces and residences are distantly separated geographically, residents are likely to adjust their residences to minimize commuting time (Clark et al., 1980, Clark and Huang, 2003). These studies, however, regard changes of workplaces as an exogenous factor, then investigate their impacts on residential mobility, ignoring the possible interaction or synergy between decisions of job change and residential migration. Waddell (1993) found that resident's decision on job change is not exogenous to residential location choices. Similarly, Ross (1998) demonstrated that residential housing adjustments in the housing market and changes of jobs are interlinked. Zax $(1987,1991,1994)$ argues that due to resident's commuting behavior and the existence of other unobservable personal attributes, residential migration and job changes are interrelated. Under the hypothesis of a single-centered urban structure, there exists a substitution mechanism between residential migration and changes of workplace. In order to shorten commuting time and reach a new equilibrium, residents can either make housing location adjustments, or change their original jobs. On the basis of searching theory, Van Ommeren et al. (1996, 1999), found a positive relationship between job changes and residential relocation solely linked by residents' commute time. Once this factor is controlled, residential migration and job change become two independent decision-making processes. Nonetheless, most of these studies do not consider the impacts of home equity and family employment structure on the joint decisions of job change and residential relocation. More importantly, the potential heterogeneity in relationships between residential mobility and job change decisions (i.e. difference in decisions among residents belonging to different socioeconomic groups) is not taken into account. On the background of urban economic reconstruction, decentralization of jobs and emerging polycentric urban spatial structures in current metropolitan areas, two research questions are of great importance and interest. What is the relationship between residential migration and changes in workplace? And is there heterogeneity in this relationship?

Transitional Chinese cities are suitable cases to answer the above questions. China's urban transformation not only includes institutional transformation but also includes the transformation of social space and is a relatively complex ongoing process (Wu et al., 2007). 
Gradual reforms of the housing system, establishment of a land compensation system and the disintegration of the unit system have dramatically changed Chinese urban spatial structure. Current investigations of housing choices, residential mobility and changes of jobs and workplaces focus on several Chinese metropolitan areas such as Beijing (Feng et al., 2004), Guangzhou (Zhou et al., 2010), Shanghai (Liu et al., 2014), Shenzhen (Shi et al., 2000), Tianjin (Chai et al., 2000), Dalian (Cao et al., 1998) and Shenyang (Zhou et al., 1997). The methodology used in this study includes empirical research methods such as questionnaires, combined with official statistics such as census data and application of advanced statistical models. In domestic migration research, except for variables indicated by traditional urban economics and sociology theories arising from studies of developed countries such as age, income, family structure, institutional factors such as Chinese work units, household registration system (Hukou) are attracting more and more attention (Zhou, 1996, Wang, 2000, Chai et al., 2000). Through analyses of macro data from statistical yearbooks and analyses of micro survey data in Shanghai, Guangzhou, Xi'an, Tianjin, Shenzhen, Dalian and Beijing, previous research found that housing needs of the majority of urban households were not sufficiently met. Low population mobility and migration is mainly due to the institutional factor of allocation of housing units and to the psychological factor of "unit complex" (Li, 2006). Research on urban residents' change of workplaces is quite limited with a focus on migrant workers and some special groups (Hu et al., 2011). Comprehensive analyses of residential and employment conditions of urban residents focus on testing the spatial match/mismatch hypothesis (e.g., Zheng et al., 2007). Song et al. (2007) found that industrial suburbanization and residential suburbanization were not synchronized, and job and residence separation created an employment space dislocation. Zhou and Yan (2006) took Guangzhou as an example, analyzed Guangzhou's employment-residence balance and macro level spatial organization pattern of them. However, there is not much literature on the interaction mechanism between residential migration and job change decisions under the background of transitional Chinese cities. This is due to the fact that these studies either consider job change as an exogenous variable in the residents' life course (Liu et al., 2007; $\mathrm{Li}, 2004$ ) or discuss changes of urban employment/residential spatial structures caused by residential migration and work change (Liu et al., 2009; Liu et al., 2011; Zhang et al., 2003; Zheng et al., 2005; Meng, 2009).

Based on this, with Beijing as a case study, we attempt to answer two questions: 1) are the residential migration decision and the job change decision independent of each other, or are they a synergistically interacting decision-making process? 2) If it is a synergistic decision-making process, how do home equity, household registration system and family employment structure impact this collaborative decision-making process? Through this study, we aim to understand the macroscopic evolution of urban spatial structure from a micro perspective and to provide a scientific and rational decision-making basis for the government to guide urban spatial structure adjustment and optimization.

\section{Theoretical basis and econometric model}

In order to directly express the relationship between the decision-making processes of residential migration and work change, we express the marginal probability of residential mi- 
gration $\mathrm{P}(\mathrm{M})$ as:

$$
\mathrm{P}(\mathrm{M})=\mathrm{P}(\mathrm{M} \cap \mathrm{Q})+\mathrm{P}(\mathrm{M} \cap \mathrm{NQ})
$$

where $\mathrm{P}(\mathrm{M} \cap \mathrm{Q})$ is the joint probability of residential migration and job changes, and $\mathrm{P}(\mathrm{M} \cap \mathrm{NQ})$ is the joint probability of residential migration and no job change.

$$
\begin{gathered}
\mathrm{P}(\mathrm{M} \cap \mathrm{Q})=\mathrm{P}(\mathrm{M}) * \mathrm{P}(\mathrm{Q} \mid \mathrm{M})=\mathrm{P}(\mathrm{Q}) * \mathrm{P}(\mathrm{M} \mid \mathrm{Q}) \\
\mathrm{P}(\mathrm{M} \cap \mathrm{NQ})=\mathrm{P}(\mathrm{M}) * \mathrm{P}(\mathrm{NQ} \mid \mathrm{M})=\mathrm{P}(\mathrm{NQ}) * \mathrm{P}(\mathrm{M} \mid \mathrm{NQ})
\end{gathered}
$$

where $\mathrm{P}(\mathrm{Q})$ is the marginal probability of job changes, $\mathrm{P}(\mathrm{Q} \mid \mathrm{M}), \mathrm{P}(\mathrm{M} \mid \mathrm{Q}), \mathrm{P}(\mathrm{NQ} \mid \mathrm{M})$ and $\mathrm{P}(\mathrm{M} \mid \mathrm{NQ})$ are conditional probabilities. As can be seen from equation (2) and (3), the probability of residential migration is directly associated with the probability of work changes. Similarly, we can take the work change probability $\mathrm{P}(\mathrm{Q})$ and use the same method to express the marginal probability and conditional probability function for residential migration, indicating that residential migration and job changes are an interrelated decision-making process. Only by regarding the two decisions as a synergistic decision-making process can we more accurately identify factors of individuals' residential relocation and job change decisions.

On the basis of the above theories, we employ the bivariate discrete choice model for studying the synergistic decision-making process of residential migration and job changes. The bivariate discrete choice model considers the two decision-making processes as a joint decision-making process by assuming that the random errors from the residential migration decision-making equation and the job change decision equation to be correlated. This model can be expressed as:

$$
\begin{gathered}
y i R^{*}=\mathrm{f}(\mathrm{Zi}, H i, I i, O i, \mathrm{Ci})+\epsilon i R, y i R=1 \text { if } y i R^{*}>0, y i R=0 \text { otherwise } \\
y i J^{*}=\mathrm{f}(\mathrm{Zi}, H i, I i, O i, C i)+\epsilon i J, y i J=1 \text { if } y i J^{*}>0, y i J=0 \text { otherwise } \\
{[\epsilon i R, \epsilon i J] \sim N 2[0,0,1,1, \rho],-1<\rho<1}
\end{gathered}
$$

Equations (4) and (5) respectively show the residential migration equation and job change equation, $\mathrm{Zi}$ represents residents' age, income and education level attributes, $\mathrm{Hi}$ represents housing tenure attributes, Ii represents household registration system attributes, Oi represents types of occupation of each resident, including government, state-owned enterprises, teachers and researchers, technology-intensive occupations, labor-intensive occupation and freelancers, and $\mathrm{Ci}$ represents one-way commuting time before residents changing residences or jobs.

$\epsilon i R$ and $\epsilon i J$ denote the random error term in the residential mobility equation and the job change equation, $\operatorname{cov}(\epsilon i R, \epsilon i J)=0$ describes residential migration and job changes as two independent decision-making process, $\operatorname{cov}(\epsilon i R, \epsilon i J) \neq 0$ describes residential mobility decisions and job change decisions as interrelated or as a joint decision-making process. This article assumes that the random error terms of the residential mobility and job change equations follow a two-dimensional normal distribution $(N 2[0,0,1,1, \rho])$. The Bivariate Probit model is used to estimate the two equations simultaneously, while a statistical test of $\rho=0$ verifies whether residential migration and work change are a synergistic decision-making process. 


\section{Data and model variables}

Data used in this paper are from the 2009 Beijing urban living environment assessment and preference questionnaire which is conducted mainly through a stratified sampling strategy based on the population density distribution in Beijing (Figure 1). The questionnaire includes each respondent's residential and work status, commuting time, choices of transport mode, residential migration in the last five years, job changes, income, current residential location, age, gender, education level, family employment structure and other socioeconomic status attributes. In total, 8749 questionnaires were issued and there were 5089 valid ones. For the purpose of this study, samples without complete information on residential mobility and job change in the last five years are further deleted. Respondents who are retired and thus do not have job change decisions, as well as respondents whose residential relocation decisions are (negatively) made due to government infrastructure development and urban renewal, are also excluded. The final sample size is 2074 and simple statistical descriptions of the data and variables are shown in Table 1.
Table 1 Statistical descriptions of the data and variables

\begin{tabular}{lc}
\hline \multicolumn{1}{c}{ Variables } & Percentage/Mean \\
\hline Residential move & $20.73 \%$ \\
Job change & $10.90 \%$ \\
Age & \\
30-40 & $34.43 \%$ \\
$40-50$ & $22.37 \%$ \\
50-60 & $5.64 \%$ \\
Family income (10 ${ }^{4}$ yuan/month) & \\
0.3-0.5 & $26.42 \%$ \\
0.5-1 & $41.37 \%$ \\
1-1.5 & $15.62 \%$ \\
$\quad$ 1.5 & $6.08 \%$ \\
Education & \\
High school & $22.76 \%$ \\
College & $65.04 \%$ \\
Postgraduate & $8.44 \%$ \\
Occupation & \\
Skill intensive & $36.16 \%$ \\
Labor intensive & $36.31 \%$ \\
Freelance & $8.10 \%$ \\
Household employment & \\
structure & \\
Multiworkers & \\
Household registration & \\
Non-migrator & \\
Housing tenure & \\
Buy & \\
\hline & \\
\hline
\end{tabular}

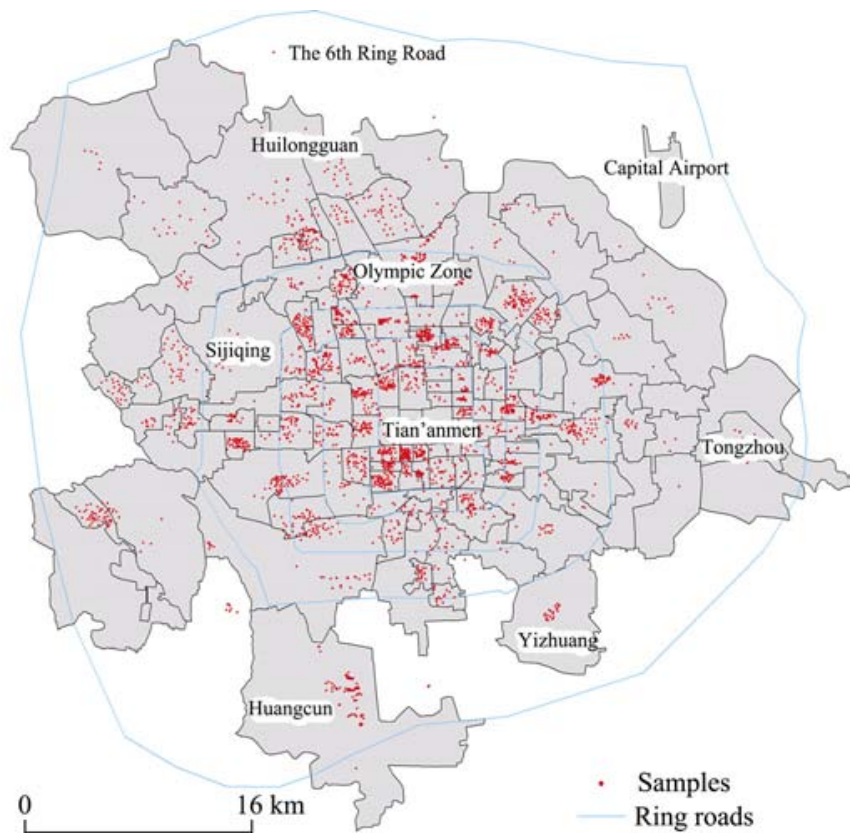

Figure 1 The distribution of samples in Beijing 


\section{Model estimation results}

In this section, bivariate probit models are employed to estimate equations (4) and (5) simultaneously and to test the inter-correlation of residents' residential migration and work change decisions. Furthermore, in order to analyze the heterogeneity in the decision-making processes of residents with different socioeconomic backgrounds, the entire sample was divided into different groups, namely, homeowners and renters, people with or without Beijing residence permit (Hukou) and families with a single worker or multiworkers. These sub-samples were further estimated separately.

\subsection{Overall results}

Tables $2-4$ show the model estimation results. In terms of the correlation between decisions of residential mobility and job change, we find that the correlation coefficients $(\rho)$ are highly significant (99\% confidence level) in all models except for Model 2 in which the correlation coefficient is significant at $95 \%$ confidence level. The statistical tests for the independence between decisions of residential migration and work change (Likelihood test of independence) show that simultaneous estimation of the two decision-making processes provides a significantly better model fit when compared to separately estimating the two decisionmaking processes. This indicates that decisions of residential relocation and job change are interacting with each other and thus a synergistic decision-making process.

The random error terms of the residential migration equation and the job change equation have a significant positive correlation, indicating that in the restructuring of urban space in Beijing, there is a mutually reinforcing mechanism between residents' housing adjustment in the housing market and work adjustment in the labor market. This is in contrast with findings from Zax $(1991,1994)$ that regard residential migration and job change as a substitution process, that is, resident tends to achieve at a new spatial equilibrium either by adjusting the location of their residence or changing jobs to shorten commuting costs, under the assumption of a single-centered urban spatial structure.

Moreover, there is significant heterogeneity in terms of the intensity of the link between decisions of residential mobility and job change among people with different characteristics. The extent of interdependency of the two decision-making processes of residents without formal Beijing household registration (migrants), rental households and single worker families is much larger than that of local Beijing residents, homeowners and multi-worker families (Tables 2-4). The household registration system is an important institutional factor that can impose strong constraints on individuals' decisions in the housing market and labor market especially for migrants. For example, besides the fact that non-residents of Beijing cannot enjoy various social benefits enjoyed by permanent residents of Beijing, with respects to home ownership purchase especially in state-owned enterprises and institutions, migrants are subject to much larger constraints compared to local residents. Migrant workers with low levels of education are more likely to move with changes of jobs or to change jobs if their residences change. The probability of a simultaneous adjustment of jobs and housing location is high for rental households due to the low cost of housing adjustment. Once the rental households find more suitable houses in the housing market, the probability of adjusting their original workplaces is also high due to the consideration of reducing commut 
ing costs and reaching a new spatial equilibrium. It can be expected that for renters without Beijing household registration, the positive correlation between decisions of residential relocation and job change will be considerably large. For multi-worker families, the cost of housing adjustment will be large and family members' general spatial equilibrium factors are more complex (Clark et al., 1999, Clark et al., 2003), so the residential migration and job changes affect each other less strongly than in single worker families.

Table 2 Estimate results of bivariate probit models among all households, owners and renters

\begin{tabular}{|c|c|c|c|c|c|c|c|c|c|c|c|c|}
\hline \multirow{3}{*}{ Variables } & \multicolumn{4}{|c|}{ All samples (Model 1) } & \multicolumn{4}{|c|}{ Owners (Model 2) } & \multicolumn{4}{|c|}{ Renters (Model 3) } \\
\hline & \multicolumn{2}{|c|}{ Residential move } & \multicolumn{2}{|c|}{ Job change } & \multicolumn{2}{|c|}{ Residential move } & \multicolumn{2}{|c|}{ Job change } & \multicolumn{2}{|c|}{ Residential move } & \multicolumn{2}{|c|}{ Job change } \\
\hline & $\beta$ & Std.error & $\beta$ & Std.error & $\beta$ & Std.error & $\beta$ & Std.error & $\beta$ & Std.error & $\beta$ & Std.error \\
\hline Constant & $0.5378^{*}$ & 0.3246 & -0.7314 & 0.2924 & -0.1768 & 0.4738 & -1.3496 & 0.4752 & 0.3768 & 0.5475 & $-0.7175^{*}$ & 0.4386 \\
\hline \multicolumn{13}{|l|}{ Age } \\
\hline $30-40$ & -0.0521 & 0.0756 & -0.0922 & 0.0877 & 0.0811 & 0.0929 & -0.1037 & 0.1096 & $-0.3169^{* *}$ & 0.1371 & -0.0881 & 0.1522 \\
\hline $40-50$ & $-0.3365^{* * *}$ & 0.0959 & $-0.2838^{* *}$ & 0.1132 & $-0.2406^{* *}$ & 0.1110 & $-0.2258^{*}$ & 0.1289 & $-0.6201^{* * *}$ & ${ }^{*} 0.2154$ & $-0.5957^{* *}$ & 0.2700 \\
\hline $50-60$ & $-0.3814^{* *}$ & 0.1721 & -0.0852 & 0.1858 & -0.2232 & 0.1926 & -0.2146 & 0.2252 & $-0.9816^{* *}$ & 0.4165 & 0.2253 & 0.3716 \\
\hline \multicolumn{13}{|l|}{$\begin{array}{l}\text { Family income } \\
\left(10^{4} \text { yuan/month) }\right.\end{array}$} \\
\hline $0.3-0.5$ & -0.0934 & 0.1229 & 0.1027 & 0.1399 & -0.1078 & 0.1733 & 0.1872 & 0.2072 & 0.0121 & 0.1862 & 0.1036 & 0.2007 \\
\hline $0.5-1$ & -0.0553 & 0.1221 & -0.0304 & 0.1419 & 0.0005 & 0.1712 & 0.0698 & 0.2096 & -0.1075 & 0.1866 & -0.0851 & 0.2037 \\
\hline $1-1.5$ & -0.0355 & 0.1421 & 0.1136 & 0.1630 & 0.1225 & 0.1886 & $0.3830 *$ & 0.2243 & $-0.4477^{*}$ & 0.2513 & $-0.7118^{* *}$ & 0.3155 \\
\hline$>1.5$ & 0.2729 & 0.1724 & -0.0168 & 0.2104 & 0.3423 & 0.2114 & 0.0413 & 0.2703 & 0.1394 & 0.4408 & 0.2056 & 0.4427 \\
\hline \multicolumn{13}{|l|}{ Education } \\
\hline High school & 0.2608 & 0.1993 & 0.0796 & 0.2161 & 0.3661 & 0.3138 & 0.3258 & 0.3479 & 0.0842 & 0.2884 & -0.2539 & 0.3027 \\
\hline College & $0.3836 * *$ & 0.1953 & 0.2250 & 0.2117 & 0.5029 & 0.3101 & 0.4149 & 0.3449 & 0.1965 & 0.2801 & -0.0046 & 0.2923 \\
\hline Postgraduate & $0.3689 *$ & 0.2251 & 0.2384 & 0.2510 & 0.4692 & 0.3340 & 0.3448 & 0.3786 & 0.2539 & 0.3907 & 0.2174 & 0.4192 \\
\hline \multicolumn{13}{|l|}{ Occupation } \\
\hline Skill intensive & -0.0975 & 0.0926 & $0.2025^{*}$ & 0.1155 & -0.0851 & 0.1032 & 0.1675 & 0.1307 & -0.1116 & 0.2213 & 0.4028 & 0.2692 \\
\hline Labor intensive & -0.1457 & 0.0957 & 0.1663 & 0.1188 & $-0.1825^{*}$ & 0.1097 & 0.1229 & 0.1374 & -0.0134 & 0.2177 & 0.3992 & 0.2659 \\
\hline Freelance & $-0.3010^{* *}$ & 0.1431 & $0.2663^{*}$ & 0.1594 & $-0.4501^{* *}$ & 0.1910 & 0.2370 & 0.1981 & -0.1504 & 0.2677 & 0.4230 & 0.3131 \\
\hline \multicolumn{13}{|l|}{$\begin{array}{l}\text { Household } \\
\text { employment } \\
\text { structure }\end{array}$} \\
\hline Multiworkers & $-0.2263^{* *}$ & 0.0999 & -0.1437 & 0.1126 & $-0.2589^{* *}$ & 0.1322 & -0.2333 & 0.1500 & -0.2238 & 0.1600 & -0.0201 & 0.1743 \\
\hline \multicolumn{13}{|l|}{$\begin{array}{l}\text { Household } \\
\text { registration }\end{array}$} \\
\hline Nonmigrator & $-0.3910^{* * *}$ & 0.1061 & $-0.3234^{* * *}$ & 0.1164 & $-0.3970^{* *}$ & 0.1710 & $-0.4392^{* *}$ & 0.1879 & $-0.3502^{* *}$ & 0.1425 & -0.2122 & 0.1547 \\
\hline \multicolumn{13}{|l|}{ Housing tenure } \\
\hline Buy & $-0.6826^{* * *}$ & 0.0788 & $-0.4233^{* * *}$ & 0.0900 & & & & & & & & \\
\hline Commuting time & 0.0045 & 0.0523 & -0.0259 & 0.0592 & -0.0100 & 0.0688 & 0.0027 & 0.0807 & $0.0488^{* *}$ & 0.0217 & -0.0397 & 0.0899 \\
\hline $\mathrm{N}$ & \multicolumn{4}{|c|}{2074} & \multicolumn{4}{|c|}{1607} & \multicolumn{4}{|c|}{467} \\
\hline Log likelihood & \multicolumn{4}{|c|}{-1622.2713} & \multicolumn{4}{|c|}{-1087.7912} & \multicolumn{4}{|c|}{-508.92} \\
\hline $\begin{array}{l}\text { Correlation } \\
\text { coefficient }(\rho)\end{array}$ & \multicolumn{4}{|c|}{$0.2461^{* * *}(0.0507)$} & \multicolumn{4}{|c|}{$0.1519^{* *}(0.0671)$} & \multicolumn{4}{|c|}{$0.3788^{* * * *}(0.0783)$} \\
\hline $\begin{array}{l}\text { Likelihood test of } \\
\text { independence }(\mathrm{P})\end{array}$ & \multicolumn{4}{|c|}{$22.1563(0.0000)$} & & 5.0216 & (0.0250) & & & 20.0436 & $(0.0000)$ & \\
\hline
\end{tabular}


Table 3 Estimate results of bivariate probit models among nonmigrators and migrator

\begin{tabular}{|c|c|c|c|c|c|c|c|c|}
\hline \multirow{3}{*}{ Variables } & \multicolumn{4}{|c|}{ Non-migrator (Model 4) } & \multicolumn{4}{|c|}{ Migrant (Model 5) } \\
\hline & \multicolumn{2}{|c|}{ Residential move } & \multicolumn{2}{|c|}{ Job change } & \multicolumn{2}{|c|}{ Residential move } & \multicolumn{2}{|c|}{ Job change } \\
\hline & $\beta$ & Std.error & $\beta$ & Std.error & $\beta$ & Std.error & $\beta$ & Std.error \\
\hline Constant & 0.0856 & 0.3900 & $-0.91862^{* *}$ & 0.35946 & 1.1040 & 0.8250 & -0.695022 & 0.607114 \\
\hline \multicolumn{9}{|l|}{ Age } \\
\hline $30-40$ & 0.0652 & 0.0822 & -0.0898 & 0.0966 & $-0.7233^{* * *}$ & 0.2176 & -0.2361 & 0.2259 \\
\hline $40-50$ & $-0.2427^{* *}$ & 0.1002 & $-0.2638^{* *}$ & 0.1186 & $-0.9058^{* *}$ & 0.4391 & -0.6947 & 0.4515 \\
\hline $50-60$ & $-0.3200^{*}$ & 0.1790 & -0.1258 & 0.1949 & -0.6286 & 0.8218 & -0.1125 & 0.7947 \\
\hline \multicolumn{9}{|l|}{$\begin{array}{l}\text { Family income } \\
\left(10^{4} \text { yuan/month) }\right.\end{array}$} \\
\hline $0.3-0.5$ & -0.1596 & 0.1367 & 0.0462 & 0.1590 & 0.1900 & 0.2952 & $0.4321^{* * * *}$ & 0.1546 \\
\hline $0.5-1$ & -0.1365 & 0.1357 & -0.0105 & 0.1604 & 0.2586 & 0.2981 & -0.1899 & 0.3179 \\
\hline $1-1.5$ & -0.1005 & 0.1551 & 0.1394 & 0.1807 & 0.3583 & 0.4081 & 0.0130 & 0.4279 \\
\hline$>1.5$ & 0.1245 & 0.1885 & -0.0611 & 0.2382 & $1.2338^{* *}$ & 0.5055 & 0.1893 & 0.4846 \\
\hline \multicolumn{9}{|l|}{ Education } \\
\hline High school & 0.2628 & 0.2565 & 0.0157 & 0.2655 & 0.2798 & 0.3640 & 0.0349 & 0.3783 \\
\hline College & $0.4071^{*}$ & 0.2529 & 0.1238 & 0.2622 & 0.4317 & 0.3513 & 0.2653 & 0.3589 \\
\hline Postgraduate & 0.4078 & 0.2786 & 0.1947 & 0.2973 & 0.1043 & 0.5451 & -0.0948 & 0.5792 \\
\hline \multicolumn{9}{|l|}{ Occupation } \\
\hline Skill intensive & -0.0436 & 0.0979 & 0.1673 & 0.1235 & $-0.7525^{* *}$ & 0.3301 & 0.4245 & 0.3596 \\
\hline Labor intensive & -0.1364 & 0.1010 & 0.1839 & 0.1256 & -0.4463 & 0.3522 & 0.0762 & 0.3846 \\
\hline Freelance & $-0.2457^{*}$ & 0.1369 & $0.2756^{*}$ & 0.154467 & $-0.7395^{*}$ & 0.4264 & 0.2641 & 0.4494 \\
\hline \multicolumn{9}{|l|}{$\begin{array}{l}\text { Household employment } \\
\text { structure }\end{array}$} \\
\hline Multiworkers & $-0.2249^{* *}$ & 0.1116 & $-0.21439^{*}$ & 0.1267 & -0.1829 & 0.2426 & 0.0797 & 0.2553 \\
\hline \multicolumn{9}{|l|}{ Housing tenure } \\
\hline Buy & $-0.6894^{* * *}$ & 0.0852 & $-0.4398^{* * *}$ & 0.0975 & $-0.6518^{* * *}$ & 0.2341 & -0.2544 & 0.2448 \\
\hline Commuting time & 0.0186 & 0.0586 & -0.0174 & 0.0673 & -0.0200 & 0.1278 & -0.1184 & 0.1313 \\
\hline $\mathrm{N}$ & \multicolumn{4}{|c|}{1869} & \multicolumn{4}{|c|}{205} \\
\hline Log likelihood & \multicolumn{4}{|c|}{-1389.1763} & \multicolumn{4}{|c|}{-210.7548} \\
\hline Correlation coefficient $(\rho)$ & \multicolumn{4}{|c|}{$0.1886^{* * *}(0.0571)$} & \multicolumn{4}{|c|}{$0.5397^{* * *}(0.1096)$} \\
\hline $\begin{array}{l}\text { Likelihood test of } \\
\text { independence }(\mathrm{P})\end{array}$ & \multicolumn{4}{|c|}{$10.5122(0.0012)$} & \multicolumn{4}{|c|}{$17.4117(0.0000)$} \\
\hline
\end{tabular}

\subsection{Group results}

From bivariate probit model estimation results (Model 1 to Model 7), it can be seen that people aged 40-50 have a statistically significant lower probability of relocating residences and changing jobs than residents under 30. This situation is particularly evident for homeowners, renters, Beijing household registration holders, and multi-worker families. This is mainly because for residents aged 40-50, their work proficiency, status in the workplace and loyalty to the work unit will gradually increase, leading to a weak motivation of job changes (Bartel, 1979). Residents with Beijing household registration in multi-worker families also 
Table 4 Estimate results of bivariate probit models among single worker and multi-worker households

\begin{tabular}{|c|c|c|c|c|c|c|c|c|}
\hline \multirow{3}{*}{ Variables } & \multicolumn{4}{|c|}{ Single worker household (Model 6) } & \multicolumn{4}{|c|}{ Single worker household (Model 7) } \\
\hline & \multicolumn{2}{|c|}{ Residential move } & \multicolumn{2}{|c|}{ Job change } & \multicolumn{2}{|c|}{ Residential move } & \multicolumn{2}{|c|}{ Job change } \\
\hline & $\beta$ & Std.error & $\beta$ & Std.error & $\beta$ & Std.error & $\beta$ & Std.error \\
\hline Constant & 1.1412 & 0.7533 & -1.1286 & 0.6464 & 0.3151 & 0.3764 & -0.8269 & 0.3572 \\
\hline \multicolumn{9}{|l|}{ Age } \\
\hline $30-40$ & 0.0409 & 0.1989 & $-0.4047 *$ & 0.2373 & -0.0710 & 0.0824 & -0.0454 & 0.0956 \\
\hline $40-50$ & $-0.6708^{* *}$ & 0.3333 & -0.3976 & 0.3497 & $-0.3056^{* * *}$ & 0.1014 & $-0.2535^{* *}$ & 0.1209 \\
\hline $50-60$ & -0.5666 & 0.6146 & 1.1108 & 1.4833 & $-0.3643^{* *}$ & 0.1809 & -0.3086 & 0.2193 \\
\hline \multicolumn{9}{|l|}{$\begin{array}{l}\text { Family income } \\
\left.\text { (10 } 10^{4} \text { yuan/month }\right)\end{array}$} \\
\hline $0.3-0.5$ & -0.0590 & 0.2255 & 0.2575 & 0.2479 & -0.1942 & 0.1545 & 0.0116 & 0.1794 \\
\hline $0.5-1$ & 0.1525 & 0.2703 & -0.0938 & 0.3168 & -0.1806 & 0.1490 & -0.0737 & 0.1748 \\
\hline $1-1.5$ & 0.3728 & 0.4446 & 0.0810 & 0.4876 & -0.1664 & 0.1659 & 0.0777 & 0.1918 \\
\hline$>1.5$ & $0.9112^{*}$ & 0.5337 & -0.0667 & 0.6866 & 0.1165 & 0.1958 & -0.0599 & 0.2383 \\
\hline \multicolumn{9}{|l|}{ Education } \\
\hline High school & 0.4681 & 0.3751 & 0.3398 & 0.3185 & 0.1941 & 0.2432 & 0.2442 & 0.2800 \\
\hline College & $0.5969^{*}$ & 0.3645 & 0.0726 & 0.3303 & 0.3209 & 0.2387 & 0.3245 & 0.2750 \\
\hline Postgraduate & 0.5822 & 0.4955 & 0.1976 & 0.3982 & 0.3091 & 0.2684 & 0.3301 & 0.3134 \\
\hline \multicolumn{9}{|l|}{ Occupation } \\
\hline Skill intensive & 0.0493 & 0.2754 & 0.3398 & 0.3185 & -0.1083 & 0.0996 & $0.2043^{*}$ & 0.1265 \\
\hline Labor intensive & -0.1495 & 0.2968 & 0.0726 & 0.3303 & -0.1291 & 0.1023 & $0.2111^{*}$ & 0.1296 \\
\hline Freelance & -0.3561 & 0.3804 & 0.1976 & 0.3982 & $-0.2709^{*}$ & 0.1585 & $0.3396^{* *}$ & 0.1773 \\
\hline \multicolumn{9}{|l|}{ Household registration } \\
\hline Nonmigrator & $-0.2355^{* * *}$ & 0.2445 & -0.1105 & 0.2678 & $-0.4252^{* * *}$ & 0.1197 & $-0.3972^{* * *}$ & 0.1312 \\
\hline \multicolumn{9}{|l|}{ Housing tenure } \\
\hline Buy & -0.8493 & 0.2036 & $-0.5286^{* *}$ & 0.2277 & $-0.6512^{* * *}$ & 0.0868 & $-0.4062^{* * *}$ & 0.0997 \\
\hline Commuting time & 0.2601 & 0.2369 & 0.0651 & 0.1515 & 0.0552 & 0.0577 & -0.0526 & 0.0652 \\
\hline $\mathrm{N}$ & \multicolumn{4}{|c|}{274} & \multicolumn{4}{|c|}{1800} \\
\hline Log likelihood & \multicolumn{4}{|c|}{-240.8636} & \multicolumn{4}{|c|}{-1362.95} \\
\hline Correlation coefficient $(\rho)$ & \multicolumn{4}{|c|}{$0.3633^{* * *}(0.1229)$} & \multicolumn{4}{|c|}{$0.2330^{* * *}(0.0560)$} \\
\hline $\begin{array}{l}\text { Likelihood test of } \\
\text { independence }(\mathrm{P})\end{array}$ & \multicolumn{4}{|c|}{$7.5433(0.0060)$} & \multicolumn{4}{|c|}{$16.4065(0.0001)$} \\
\hline
\end{tabular}

have such stability characteristics, and therefore are less motivated to take decisions of residential migration.

In the bivariate probit model for renters (Model 3), high-income families tend to have a lower probability of residential relocation and job change than families with low monthly income. However, in other models, family income does not have significant influences in the probability of residential migration. This is possibly because of the correlations between the income variable and age, level of education and home equity variables. Residents with a bachelor or postgraduate degree tend to have a significantly larger probability of residential migration than those only finishing high school or lower level education. Surprisingly, education does not have a significant effect on the decision of job change. Probability of 
changing jobs for residents in a technology-intensive industry and freelancers is significantly larger than that of residents who work in government or state-owned enterprises.

The impact of the household registration system on residents' housing and workplace adjustments is statistically significant at the 99\% confidence level. Residents with Beijing household registration have a smaller probability of residential migration or work change than migrants. Home equity is also an important factor of residential migration and job change decisions: the probability of changing residences and jobs for homeowners is significantly lower than that for renters, which is in accordance with findings in $\mathrm{Li}$ (2004).

Commuting time has no significant effects on the adjustments of residences and jobs in most model specifications except for Model 3 and Model 6 in which commuting time exerts significant influences on the probability of residential migration for renters and single-worker families. This indicates that in the context of transitional Beijing, residents with different socioeconomic characteristics can have varying responses to changes of commuting time. For rental households and single-worker families, housing adjustment costs are relatively small when compared to other residents.

\subsection{An explanation on the heterogeneity in the synergistic decision-making process}

In the period of a planned economy, for most of urban residents, employment in a work unit usually means a lifelong insurance and thus mobility in labor market was very rare. After the policy of reform and opening up, the original system of lifetime employment was gradually challenged by a market mechanism, and labor market mobility became more frequent. Changes of jobs or workplaces can induce people to choose new residences that are in close proximity of their new workplace. In terms of causes of residential mobility, in the context of a transitional market oriented economy, family housing demand, institutional factors and environmental pressure are three most important reasons (Chai et al., 2009). This is in contrast with traditional residential relocation theories that regard the mismatch between current housing conditions and future housing expectation to be the most important factor of residential mobility.

In the interdependent decision-making processes of residential mobility and job change, differences in housing equity, family employment structure and household registration condition cause a heterogeneity effect: the intensity of correlations between the two decision processes vary significantly among different groups of residents. Household registration system is an important institutional factor, imposing significant constraints on residents' behaviors in the housing and labor markets. There are many types of social benefits for permanent urban residents that are not equally enjoyed by non-registered residents (migrants) in Beijing. Multi-worker families face a more complex situation when considering changes of residences and jobs because of further considerations of children's education and medical care services for the elderly (Clark et al., 1999).

\section{Conclusions and discussion}

Based on a large survey data, this paper employs bivariate probit modelling approach to investigate the dependence between decisions of residential relocation and job change and to explore the possible heterogeneity effect in the two decision-making processes. Several con- 
clusions are as follows:

(1) Decisions of residential migration and job change are inter-correlated (the correlation coefficients between two decision-making processes are highly significant), and thus housing adjustments residents make in the housing market and work adjustments in the labor market have a positive feedback mechanism.

(2) There is significant heterogeneity in the synergistic decision-making process among groups of residents with different socioeconomic characteristics. The household registration system has a strong impact on the interaction between the residential migration decision and the job change decision. The degree of interaction for migrants is much larger than for residents with Beijing household registration. This indicates that the probability of changes in housing for migrants will be much higher than permanent residents once job change occurs and vice versa, which is perhaps one of the reasons for the currently high turnover of housing and jobs in the migrant population in Beijing. Similarly, the link between decisions of residential mobility and job change for renters and single-worker families is stronger than that for homeowners and multi-worker families.

(3) Commuting costs only play a significant role in the residential decisions of rental households, indicating that residents of different socioeconomic attributes have quite different responses to commuting time. When there are exogenous shocks resulting in an increase of commuting time for rental households, residents tend to adjust their existing houses rather than workplaces to shorten commuting time and reach a new spatial equilibrium.

\section{Acknowledgement}

We are very grateful to Prof. Richard Harris, School of Geographical Sciences, University of Bristol, for providing very helpful comments on the first draft of this paper and polishing this final version.

\section{References}

Aassve A, Betti G, Mazzuco S et al., 2007. Marital disruption and economic well-being: A comparative analysis. Journal of the Royal Statistical Society, 170: 781-799.

Bartel A P, 1979. The migration decision: What role does job mobility play? The American Economic Review, 69(5): 775-786.

Brown L A, Moore E G, 1970. The interurban migration process: A perspective. Geografiska Annaler Series B, 52: $1-13$.

Cao Guangzhong, Chai Yanwei, 1998. On the urban internal structure transformation and suburbanization in Dalian city. Chinese Geographical Science, (3): 234-241. (in Chinese)

Chai Yanwei, Chen Lingji, 2009. The residential mobility of urban Danwei residents: A life course approach. Urban Planning International, 24(5): 7-14. (in Chinese)

Chai Yanwei, Chen Lingji, Zhang Chun, 2007. Transformation of Danwei System: An angle of view on city changes in China. World Regional Studies, (2): 21-30. (in Chinese)

Chai Yanwei, Hu Zhiyong, Wu Zongqing, 2000. On characteristics and mechanism of intra-urban residents' migration in Tianjin city, China. Geographical Research, 19(4): 391-399. (in Chinese)

Chen Yinyin, 1995. Occupational Structure and Flow. Beijing: Oriental Press, 51-53. (in Chinese)

Clark W A V, Burt J, 1980. The impact of workplace on residential relocation. Annals of the Association of American Geographers, 70(1): 59-67. 
Clark W A V, Huang Y, 2003. The life course and residential mobility in British housing markets. Environment and Planning A, 35: 323-339.

Clark W A V, Huang Y, Withers S D, 2003. Does commuting distance matter? Commuting tolerance and residential change. Regional Science and Urban Economics, 33: 199-221.

Clark W A V, Onaka J, 1982. Life cycle and housing adjustment as explanations of residential mobility. Urban Studies, 20: 47-57.

Clark W A V, Withers S D, 1999. Changing jobs and changing houses: Mobility outcomes of employment transitions. Journal of Regional Science, 39(4): 653-673.

Ermisch J, Jenkins S P, 1999. Retirement and housing in later life: Evidence from the British household panel survey. Labor Economics, (6): 311-333.

Feng Jian, Zhou Yixing, 2004. Intra-urban migration and correlative spatial behavior in Beijing in the process of suburbanization: Based on 1000 questionnaires. Geographical Research, 23(2): 227-242. (in Chinese)

Hu Fengxia, Yao Xianguo, 2011. Urban employee's behaviors of choosing the informal employment and labor market segmentation: An analysis based on a panel data. Journal of Zhejiang University (Humanities and Social Sciences), 41(2): 191-199. (in Chinese)

Lee B A, Oropesa R S, Kanan J W, 1994. Neighborhood context and residential mobility. Demography, 31: 249-265.

Li Changxia, 2006. A social geographical study on old people’s history of residential mobility in Beijing [D]. Beijing: Peking University. (in Chinese)

Li Jun, Li Xiaojian, 2008. Study on influence factor of rural residents' migration intention. Economic Geography, 28(3): 455-459. (in Chinese)

Li S M, Siu Y M, 2001. Residential mobility and urban restructuring under market transition: A case study of Guangzhou, China. Professional Geographer, 53(2): 219-229.

Li Siming, 2004. Life course and residential mobility in Beijing, China. Environment and Planning A, 36: 27-43. (in Chinese)

Liu Baokui, Feng Changchun, Shen Bing, 2012. Characteristics of intra-urban migration of rural migrant workers in Beijing. Urban Development Studies, 19(5): 72-87. (in Chinese)

Liu Bihan, Shen Fanbu, 2011. A study on the spatial characteristics of jobs-housing structure in Beijing. Human Geography, (4): 40-47. (in Chinese)

Liu Tingting, Li Hanwei, Gao Kai, 2014. A study of housing selection of the floating population with family migration and its influencing factors: A case of Shanghai. South China Population, 29(3): 17-27. (in Chinese)

Liu Wangbao, Yan Xiaopei, 2007. Comparison of influencing factors for residential mobility between different household register types in transitional urban China: A case study of Guangzhou. Geographical Research, 26(5): 1055-1066. (in Chinese)

Liu Zhilin, Zhang Yan, Chai Yanwei, 2009. Home-work separation in the context of institutional and spatial transformation in Chinese cities: Evidence from Beijing Household Survey Data. Urban Development Studies, 16(9): 110-117. (in Chinese)

Meng Bin, 2009. The spatial organization of the separation between jobs and residential locations in Beijing. Acta Geographica Sinica, 64(12): 1457-1466. (in Chinese)

Rabe B, Taylor M, 2010. Residential mobility, quality of neighbourhood and life course events. Journal of the Royal Statistical Society: Series A (Statistics in Society), 173(3): 531-555.

Ross S L, 1998. Racial differences in residential and job mobility: Evidence concerning the spatial mismatch hypothesis. Journal of Urban Economics, 43: 112-135.

Rossi P, 1955. Why Families Move. Glencoe, IL: Free Press, 122-123.

Shi Zhonghua, Chai Yanwei, Liu Zhilin, 2000. The time-space analysis of citizen mobility characteristics of Shenzhen city. Human Geography, 15(3): 37-42. (in Chinese)

Song Jinping, Wang Enru, Zhang Wenxin et al., 2007. Housing suburbanization and employment spatial mismatch in Beijing. Acta Geographica Sinica, 62(4): 387-396. (in Chinese)

Van Kempen R, Ozuekren A S, 1998. Ethnic segregation in cities: New forms and explanations in a dynamic 
world. Urban Studies, 35: 1631-1656.

Van Ommeren J, 1998. On the job search behavior: The importance of commuting time. Land Economics, 74(4): 526-540.

Van Ommeren J, Rietveld P, Nijkamp P, 1996. Residence and workplace relocation: A bivariate duration model approach. Geographical Analysis, 28: 315-329.

Van Ommeren J, Rietveld P, Nijkamp P, 1999. Job moving, residential moving and commuting: A search perspective. Journal of Urban Economics, 46: 230-253.

Waddell P, 1993. Exogenous workplace choice in residential location models: Is the assumption valid? Geographical Analysis, 25: 65-82.

Wang Xingzhong, 2000. Study of Social Spatial Structure of Chinese Cities. Beijing: Science Press, 176-189. (in Chinese)

Wu Fulong, Ma Runchao, Zhang Jingxiang, 2007. Transition and Reconstruction: Multidimensional Perspective of Chinese Urban Development. Nanjing: Southeast University Press, 97-98. (in Chinese)

Zax J S, 1987. Quits, moves, spatial equilibrium and workplace relocation. NBER Working Paper Series No.2469.

Zax J S, 1991. The substitution between moves and quits. The Economic Journal, 101(409): 1510-1521.

Zax J S, 1994. When is a move a migration? Regional Science and Urban Economics, 24: 341-360.

Zhang Wenzhong, Liu Wang, 2003. Housings spatial distribution and residents preference on housing location in Beijing. Geographical Research, 22(6): 751-759. (in Chinese)

Zheng Siqi, Fu Yuming, Liu Hongyu, 2005. Urban households location preference: The estimation of willingness-to-pay gradient model. Progress in Geography, 24(1): 98-105. (in Chinese)

Zheng Siqi, Long Fenjie, Wang Yijun et al., 2007. Job-housing space match: A view of urban economics. Urban Problems, (6): 56-62. (in Chinese)

Zhou Chunshan, 1996. Analysis on characteristics, causes and influential aspects of urban population migration in China. Urban Planning Forum, (4): 16-21. (in Chinese)

Zhou Suhong, Liu Yulan, 2010. The situation and transition of jobs-housing relocation in Guangzhou, China. Acta Geographica Sinica, 65(2): 191-201. (in Chinese)

Zhou Suhong, Yan Xiaopei, 2006. Relationship between urban residential space and employment space and impact on resident trip in Guangzhou. City Planning Review, 30(5): 13-18. (in Chinese)

Zhou Yixing, Meng Yanchun, 1997. Shenyang's suburbanization: suburbanization comparison between China and the western countries. Acta Geographica Sinica, 52(4): 289-299. (in Chinese) 